\title{
El valle del río Magdalena en los discursos letrados de la segunda mitad del siglo XIX: territorio, enfermedad y trabajo ${ }^{1}$
}

\author{
The valley of the Magdalena River in written \\ texts from the second half of the 19th \\ century: territory, illness and work
}

Álvaro Villegas ${ }^{2}$

Resumen

Para los letrados colombianos decimonónicos el territorio patrio era diverso, en él podían encontrarse zonas que eran límites y condiciones de posibilidad de la "civilización". La cuenca del río Magdalena fue uno de estos espacios. A través de la revisión de un conjunto de escritos se describe e interpreta cómo los letrados elaboraron una representación de esta región que enfatizaba la exuberancia, la cual hacía posible la inserción nacional en el mercado mundial por medio de la agro-exportación de productos tropicales, al tiempo que traía consigo una proliferación de formas de vida fuera de control; la población regional, fue una de ellas; es ilustrativo el caso de los bogas, que fueron descritos como inmunes a las necesidades propias de los seres humanos. Es posible afirmar, entonces, que los discursos sobre la zona acentuaron la diferencia, en tanto esta aparecía como marcada de forma indeleble por la alteridad espacial y poblacional.

Palabras clave

Cuenca del río Magdalena, nación, territorio, enfermedad, trabajo

Abstract

For nineteenth-century Colombian scholars, their homeland was diverse, where areas which were limits and conditions of the possibility of 'civilisation' could be found. The basin of the Magdalena River was one of these spaces. By revising a collection of works, this article describes and interprets how scholars devised a representation of this region which emphasised the lushness of the area, which led to national participation in the global market through the agricultural exportation of tropical products, while bringing with it the development of lifestyles out of state control, such as regional populations. The case of the boga is illustrative - they were described as immune to the own needs of human beings. It is thus possible to conclude that the speeches about the area highlighted the distinctive nature of this geographical area, permanently marked by its distinctiveness in terms of both space and population.

\section{Keywords}

Basin of the Magdalena River, nation, territory, illness, work

Artículo recibido el 22 de julio de 2013 y aprobado el 14 de febrero de 2014

1 Este artículo se deriva de la tesis de doctorado en historia titulada “Heterologías: pasado, territorio y población en Colombia, 1847-1941", presentada en la Universidad Nacional de Colombia, sede Medellín.

2 Universidad Nacional de Colombia, Medellín, Colombia, aavilleg@unal.edu.co 
Universidad Pedagógica Nacional

Facultad de Humanidades

El interés por el espacio a la hora de construir un discurso sobre la nación fue una constante durante el siglo XIX en lo que hoy es Colombia. Lejos de la idea de un territorio homogéneo, los hombres de letras plantearon la existencia de profundas diferencias espaciales, que enfrentaban a las regiones apropiadas, más o menos intensamente por las elites, con los lugares que fueron definidos como desiertos. El proyecto, denominado por Germán Palacio (2001, pp. 27-28) Liberalización de la naturaleza, tuvo como blanco principal estos lugares y su fundamento fue la idea de la conquista y de la apropiación privada de la tierra. En él confluyeron las elites de ambos partidos y de diversas regiones, que buscaba la conversión de la tierra y del trabajo humano en mercancías, como condición de posibilidad del deseo civilizador decimonónico:

[...] el verdadero porvenir del país no puede ser otro que la explotación de las riquezas tropicales, y por lo mismo serán mero lujo los ferrocarriles á las regiones frías, que casi no producen artículos de exportación; en no lejano futuro por cada reinoso habrá á lo menos diez calentanos. (Vergara y Velasco, 1901, p. 367)

Para este letrado, Colombia era ante todo una tierra tropical destinada a recibir los bienes manufacturados de las regiones templadas y a exportar los productos de las tierras cálidas y ardientes - cercanas al mar o a los ríos navegables- que Europa y Norteamérica no podían producir. La liberalización de la naturaleza se vio parcialmente truncada por las divergencias de las mismas elites que la impulsaban (Rojas, 2001, pp. 185-186); además de la inestabilidad de los auges extractivos. Tal vez la principal transformación real estuvo relacionada con el incremento total y porcentual de la población asentada en las tierras bajas y medias, especialmente en las cordilleras central y occidental, y la disminución porcentual de la población nacional asentada en las tierras altas de la cordillera oriental (Palacio, 2006).

El descenso de la civilización hacia los valles y las llanuras, tal y como fue denominado en la época (Samper, 1861, p. 299), tuvo diversos frentes pero su principal incidencia se concentró en la zona fronte- riza entre Antioquia y Cauca, y en la vertiente que desciende de Cundinamarca al río Magdalena. La falta de una apropiación real de regiones, que incluso eran cercanas a los principales centros urbanos del país, no pasó desapercibida para los letrados, quienes no dudaron en criticar la negligencia del Estado y la indolencia de las elites, a las cuales pertenecían.

Las páginas restantes se concentrarán en mostrar, en primer lugar, cómo las tierras bajas fueron consideradas por los letrados colombianos como ontológicamente diferentes de las tierras altas y las implicaciones productivas que esto traía consigo; en segunda instancia, se describirán los discursos elaborados en torno a la salubridad o insalubridad de la cuenca del río Magdalena y sus consecuencias en los pobladores; finalmente, se analizarán los planteamientos realizados en torno a la capacidad de trabajo de los habitantes de esta zona, tomando como ejemplo a los bogas.

\section{Límites y posibilidades las tierras bajas}

En la escala global todo el territorio nacional se opuso a las zonas temperadas, consideradas tradicionalmente como lugares propicios para la civilización; en la escala nacional, los letrados elaboraron un inteligente ardid que tradujo esta oposición y la transformó en una dicotomía entre las tierras bajas y las tierras altas. Manuel Ancízar, manifestó al respecto:

La repentina transición de una región a otra hace muy notables sus contrastes, tanto en la configuración del suelo i en la vegetación natural, como en las habitaciones, los vestidos i las sementeras. En la rejion subandina todo es jigantesco, excepto el hombre; los desiertos se suceden apenas interrumpidos por algún pueblecillo, y las sementeras visibles se reducen a la caña, el maíz i el plátano, sembrados a trechos y rodeados del bosque al cual parecen disputar el terreno. En la rejion alta se extienden los amenos valles entapizados de menuda yerba o cuidadosamente divididos en pequeñas heredades sembradas de todo linaje de frutos menores i animadas por la humilde casita i la robusta familia del feliz propietario; ningún bosque interrumpe la vista del país, ni se andan 
muchas cuadras sin hallar habitaciones i ventas de chicha. Allí los vestidos son lijeros, desapareciendo casi enteramente la ruana, el hablar es voluble i en alta voz, los movimientos sueltos i las fisonomías despabiladas. Aquí los vestidos de bayeta, la eterna ruana, el hablar pausado con insistencia sobre algunas consonantes que suprimen los calentanos, i las fisonomías inmóviles i reservadas de la raza indíjena. Finalmente, a los senderos quebrados, sinuosos i fatigadores de la rejion baja, se suceden los caminos anchos nivelados i naturalmente firmes de la rejion alta, por los cuales las jornadas se acortan, haciéndose sin molestia del jinete ni cansancio de la bestia. Paisaje, industria, poblacion, clima, todo es diferente, todo ha variado en el breve espacio de tres horas de marcha. Dos siglos mas, i la realidad de los hechos sobrepujará a cuanto la imaginación en sus fecundas combinaciones invente acerca de la opulencia que Dios tiene reservada a estas comarcas singulares, vasto recipiente de riquezas infinitas que se acumulan en silencio esperando a sus futuros señores. Tierra como esta no ha sido creada sin grandes designios; i los designios de la Providencia no son instables como los proyectos, ni efimeros como las jeneraciones del hombre. (1853, pp. 69-70)

Esta extensa cita permite ilustrar algunos aspectos que marcaron las modalidades de representación territorial en el país: 1) la oposición entre las tierras altas y las tierras bajas era multidimensional e incluía la industria - es decir, las actividades productivas-, el clima $-\mathrm{y}$ con este las enfermedades-, la población - razas, tipos y costumbres-y, por supuesto, el paisaje; 2) el énfasis en la diversidad del territorio patrio, el cual albergaría en una mínima superficie un gran número de plantas, animales, paisajes y poblaciones; 3 ) la idea de riquezas naturales sin par y el horizonte de prosperidad material que estas sugerían; 4) la valoración positiva de las zonas frías y su oposición a las regiones cálidas caracterizadas frecuentemente como desiertos.

No obstante, la oposición entre tierras altas y bajas que parece clara inicialmente, se torna más compleja en cuanto las zonas ubicadas a menos de 1000 metros sobre el nivel del mar se consideraban necesarias para el progreso, al tiempo que su principal obstáculo. En estas se encontraban las posibilidades agrícolas y mineras que harían posible que el país hiciera parte del concierto de las naciones civilizadas, al estar plenamente integrado al mercado mundial.

En 1892, salió a la luz la primera edición de la Nueva geografía de Colombia. Escrita por regiones naturales; desde su primer capítulo, Francisco Vergara y Velasco sintetizó en varios mapas las representaciones sobre el espacio nacional que poseían una mayor potencia simbólica. En uno de estos mapas se muestra la centralidad geográfica de Bogotá; en otro el país se divide en las zonas completamente conocidas y las tierras apenas exploradas; un tercero lo divide en regiones naturales. También se presentaron una serie de mapas del relieve, basados en un principio que su autor denominó objetivo:

Supongamos que el mar sube 6,000 metros sobre su nivel actual, y por lo tanto que Colombia integra desaparece bajo sus aguas, y que luégo, mirando ese mar á vista de pájaro, hacemos que sus aguas desciendan bruscamente por capas de un kilómetro de espesura. (1901, p. 133)

De esta forma, tenemos mapas de Colombia hundida 5, 4, 3, 1 kilómetros y un mapa final titulado tierras altas y tierras bajas de Colombia, que representaría al país hundido 500 metros. Toda esta serie daría lugar a una representación que asemejaba a un archipiélago, en el que las islas que lo conformaban iban aumentado de mapa en mapa, a lo cual se sumaría a la centralidad geosimbólica de Bogotá, la proliferación de las tierras desconocidas y la fragmentación geográfica, representaciones que eran ampliamente compartidas.

La seguridad de este archipiélago, cuyo centro era la sabana bogotana, pronto se veía confrontada por un hecho ineludible: la espina dorsal del país era el río Magdalena; por este entraba buena parte de los bienes necesarios para la reproducción de la sociedad nacional y por él se movían los ciudadanos, los extranjeros y muchos de los sujetos aun no plenamente ciudadanizados. Por este río también salía un porcentaje importante de los productos que 
Universidad Pedagógica Nacional

Facultad de Humanidades

se exportaban. Eje fluvial de la vida social y punto de confluencia de los diversos intereses regionales:

En el Magdalena hay yá un interés nacional que importa sostener y cultivar, una solidaridad de esperanzas que es un vínculo de unión y de paz, lugares de reunión del antioqueño con el cundinamarqués, el boyacense, el santandereano, el bolivarense, que los hace conocerse, amarse, fundirse en un solo pensamiento de nacionalidad. (Camacho Roldán, 1897, pp. 145-146)

Esta representación, idealizada, de la comunidad nacional debe ser cuestionada, pero no invalida la percepción de que este río era un símbolo y una síntesis, para bien o para mal, del país.

Esto traía consigo el reconocimiento explícito de que las regiones más importantes para el progreso de la patria se encontraban en las tierras bajas. Una palabra podría sintetizar las descripciones de los paisajes que allí se encontraban: exuberancia. Por un lado, diversidad de especies, como lo reconocía el viajero alemán Alfred Hettner (1976, p. 42) cuando comentaba que, a diferencia de los bosques europeos caracterizados por su homogeneidad, en las selvas colombianas era difícil encontrar dos especímenes semejantes; diversidad que, además, se distribuía verticalmente, pues comenzaba a ras del suelo con las hierbas, continuaba con los arbustos y finalizaba en lo alto con árboles de buen tamaño, de los cuales, a su vez, colgaban otras plantas. A esto se sumaba, por otro lado, la abundancia de sus frutos.

La representación de una naturaleza pródiga, que brindaba a los seres humanos sus bienes, se convirtió en un lugar común. Pero, en este punto, la abundancia se deslizaba silenciosamente hacia el exceso. Felipe Pérez (1865) hizo visible la paradoja de la cuenca del río Magdalena: en una zona donde los seres humanos necesitaban esforzarse tan poco para vivir, el medio se oponía a su presencia. La respuesta a esta paradoja está implícita en la caracterización del paisaje de las zonas calientes justamente como exuberante. La exuberancia trae consigo la proliferación de la vida, proliferación que se escapa de las manos de los seres humanos, que se ven enfrentados a una naturaleza incontrolada, pletórica de animales salvajes, alimañas y enfermedades. La vida como expresión general se opone a las formas de vida particulares que son los hombres y las mujeres, especialmente si estos son blancos y civilizados. No en vano el argentino Miguel Cané quién recorrió el territorio colombiano a comienzos de la década de 1880 planteó, refiriéndose a la cuenca del río Magdalena:

Todo á lo largo del río no se encuentran sino pequeñas y miserables poblaciones, donde las gentes viven en chozas abiertas, sin más recursos que un árbol de plátanos que los alimenta, una totuma, cuyas frutas, especie de calabazas, les suministran todos los utensilios necesarios á la vida y uno ó dos cocoteros. [...]. Mientras mis ojos miran con asombro el cuadro deslumbrante de aquel suelo, el espíritu observa tristemente que esa grandeza no es más que una mortaja tropical. Así, Colombia se refugia en las alturas, lejos, muy lejos del mar y de Europa, tras los riscos escarpados que dificultan el acceso y trata de hacer allí su centro de civilización. (1992, p. 74)

La historia de la descripción de esa "mortaja tropical" es, en buena medida, el relato de las enfermedades que afectaban a quienes tenían la osadía de habitar o de transitar por esos parajes. Lejos de la res extensa, el espacio de la nación estaba completamente marcado por juicios económicos y morales que se superponían a juicios estéticos, en tanto involucraban la sensibilidad de los viajeros-letrados, cuando estos se decidían a recorrer el país sobre el que escribían. El padecimiento y las afecciones que sufrían los viajeros, cuando salían de la relativa calma y la sanidad del archipiélago de las tierras altas, coincidían con la percepción de la aparente indolencia de quienes allí habitaban. Por supuesto, no se trataba de una percepción pura, ninguna lo es, sino de una percepción construida culturalmente y que se asentaba en buena medida en la equivalencia entre la diferencia espacial y la poblacional. En este sentido, Nancy Leys Stepan (2001) y David Arnold (2001) han mostrado cómo, durante la segunda mitad del siglo XIX, lo tropical se convirtió en una categoría geográfica precisa, asociada a un conjunto de enfermedades, a unas poblaciones sociorracial- 
mente particulares y a una serie de paisajes singulares, lo cual la hacía ontológicamente diferente de las zonas temperadas.

\section{¿Un territorio insalubre?}

Francisco Vergara y Velasco (1901) comentaba al respecto que a las enfermedades nativas se sumaban las exóticas, que se aclimataban rápidamente sin que el gobierno o los particulares hicieran ningún esfuerzo para impedirlo. Para él, en las tierras calientes arremetían contra la población, el paludismo, la anemia, la malaria, la tisis, la sífilis y numerosas fiebres: la amarilla, la biliosa, la intermitente y la ética; la raza negra de estas regiones era el objetivo preferido de la forunculosis, los eczemas, la psoriasis, la cloasma, el beriberi, la elefantiasis y el escrotum. Enfermedades de tierra fría en otros lugares del mundo, como la gripa, la bronquitis, la tuberculosis y la viruela, se encuentran aquí por todo el territorio nacional. El coto, que "embrutece" a la raza humana, se encuentra tanto en las tierras altas como las bajas a juicio de este geógrafo. Sin embargo, la importancia de las regiones cálidas era tal, que su carácter malsano debía ser relativizado, pues de lo contrario el futuro de la república en su conjunto sería imposible.

Este mismo letrado (1901, p. 378) luego de su larga lista de enfermedades, aquí resumida, afirmó que hacía tiempo que no había allí grandes epidemias y que el número de colombianos que residía en las zonas con menos de 1000 metros sobre el nivel del mar era cada vez mayor, a pesar de la falta de higiene del pueblo, la ausencia de auxilios médicos y la falta de un desmonte sistemático de la selva. Los padecimientos de este segmento de la población podían ser atribuidos a múltiples causas, empezando por su misma falta de disposición para la vida civilizada. En su lección sobre el pasado, Enrique Cortés, en un escrito publicado originalmente en 1877, descartaba de tajo la tiranía del capital en las tierras bajas de la república y responsabilizaba a la atrofia intelectual, al ocio, a la falta de previsión y al aguardiente, por el mantenimiento de los pobres en la miseria:
El aguardiente es la maldición de este país. Todos los obreros y aldeanos de las tierras calientes, con la feracidad de ese clima, los altos salarios, lo barato de la tierra y los pocos gastos personales que requiere allí la vida, podrían hacer en pocos años ahorros de consideración y formar un capital, si no fuera por ese ídolo insaciable, que arrastra como una vorágine todo cuando gana el pobre, para que los sacrifique en su impúdico altar. (1896, p. 360)

Todo estaba servido, pues, para el enriquecimiento de los trabajadores manuales, menos ellos mismos, que no conocían sus verdaderos intereses. El también liberal Salvador Camacho Roldán señaló de forma coincidente que, en Tolima durante la década de 1870, es decir, durante los años finales del auge tabacalero, se presentó de forma exacerbada una enfermedad común a todo el país: la embriaguez, a la cual se le unió rápidamente el juego y la prostitución. Según el autor, estas tenían como causa el mismo carácter del ambiente:

La acción prolongada de los grandes calores produce, como primer efecto, languidez en el organismo, falta de nutrición y por consiguiente debilidad general, transmitida luego por herencia á los hijos. La anemia, el coto, las úlceras, son consecuencia inmediata; y la pereza, los vicios sobre todo el del uso de licores estimulantes, la miseria fisiológica y la del alma -mucho peor que la otra- aparecen luégo en la segunda y la tercera generación. (1897, p. 253)

Sería necesaria, una apropiación más decidida y consistente del discurso eugenésico en la década de 1920 para darle un cuerpo más sólido a este tipo de enunciados, que apelaban a la pérdida de capacidades fisiológicas y morales a través de las generaciones y que la asociaban a medios enfermizos y a comportamientos inadecuados. Durante la segunda mitad del siglo XIX y en el tránsito al siglo XX, el énfasis recayó en el ambiente y su asociación con un tipo de enfermedades específicas. La principal preocupación no fue entonces el alcohol ni ningún otro comportamiento que causara enfermedades, sino el carácter enfermizo per se de estas zonas, que provocaban, entre todas las enfermedades ya mencionadas, un sinnúmero de fiebres. 
Universidad Pedagógica Nacional

Facultad de Humanidades

Desde mediados del siglo XIX, coincidiendo con los esfuerzos por conquistar las tierras bajas, en especial las del valle del Magdalena, se puede identificar una honda preocupación por las dificultades que imponía la omnipresencia de las fiebres sobre los pobladores o viajeros. Manuel Ancízar planteaba:

Rara persona de las que bajan al Carare se liberta de fiebres intermitentes. No bastan preocupaciones: necesitase una constitución privilegiada para salir sano de entre aquellos bosques i lodazales eternos, hirviendo en putrefaccion vejetal bajo una temperatura de $27^{\circ}$ a $32^{\circ}$ del centígrado, en medio de una atmosfera cargada de olores penetrantes i casi nunca renovada en sus capas inferiores por corrientes de aire libre (1853, p. 105)

Ancízar, sus contemporáneos, e incluso algunos de sus sucesores varias décadas después, se enfrentaban a las "fiebres" con un saber que trazaba fronteras muy tenues entre ellas y que atribuía sus causas al fermento del detritus de los bosques bajo el inclemente sol, a los rápidos cambios de temperatura, a la transpiración constante, a la imprudencia natural de quienes no estaban aclimatados a estas zonas y a "la abundancia de frutas tropicales, á las que el estómago del hombre de Occidente no está habituado" (Cané, 1992, p. 65, cursivas agregadas). Nuevo ejemplo de conversión de las tierras altas en zonas temperadas, pues aquí el hombre occidental es el viajero ilustrado andino, quien, a pesar de habitar una zona latitudinalmente tropical, no está habituado a las frutas tropicales. El miembro de la ciudad letrada que se ve despojado de valor, ante la ineficacia de la escritura, en un mundo que se guiaba por otros preceptos.

La preocupación por las fiebres del Magdalena fue central para la emergencia de las geografías médicas en nuestro país (Cuervo Márquez, 1886; Esguerra, 1872; Gómez, 1886), estas fueron los primeros trabajos de epidemiología comparada. En ellas, se estudiaban vastas regiones en búsqueda de los caracteres singulares de las enfermedades locales. Los especialistas partían de que existían endemias propias de las tierras bajas, de forma análoga a los geógrafos naturalistas, quienes habían identificado seres organizados y paisajes propios de esta zona.

Los médicos, en su afán de vincular la nosología y la etiología de las enfermedades con el medio geográfico, se convertían en topógrafos y geógrafos de las epidemias, siguiendo el recorrido espacial de las afecciones e interrogando al ambiente. Estas geografías construyeron y reforzaron la idea de que esta región era una tierra envenenada, deletérea y palustre, lo cual entraba en conflicto con la necesidad de apropiarse simbólica y materialmente de esta (Villegas Vélez y Castrillón Gallego, 2006). A pesar de la especificidad desplegada en este tipo de saber, es fácil suponer que, dados los estrechos vínculos entre las elites letradas nacionales, estos planteamientos fueron conocidos, aunque sea de oídas, por los hombres de letras ajenos al ejercicio de la medicina, que se apropiaban de algunas de estas consideraciones.

A juicio de geógrafos como Agustín Codazzi (2003) y Francisco Vergara y Velasco (1901, p. 713), las tierras frías eran un sanatorium para las enfermedades de las tierras bajas, al tiempo que un criadero de hombres, los cuales debían conquistar estas últimas y vigorizar con su sangre la población de estas zonas. Así, el crecimiento poblacional de las segundas dependía de las primeras. Ambos letrados estaban de acuerdo, además de que la tala del bosque, la desecación de los pantanos y el aprovechamiento agrícola o ganadero de la tierra saneaba el medio. En síntesis, se podría plantear "que el país es sano allí donde el hombre lo ha hecho sano mediante su trabajo y civilización", como lo expresó Röthlisberger, originalmente en 1897 (1993, p. 90).

\section{La maldición de la facilidad: indolencia y trabajo en el valle del río Magdalena}

El problema era definir y encontrar la población que estuviera capacitada para hacerlo sano. Las consideraciones sobre los habitantes ribereños, los colonos y los inmigrantes ocuparon miles de páginas y litros de tinta. La indolencia de los pobladores ya asentados fue descrita una y otra vez. Si bien la naturaleza da con generosidad a los pobladores asentados a la 
ribera del río, su vida no era tan fácil por estar atrapados en esas soledades. Además, debían protegerse de las inundaciones, de los animales salvajes, de la fiebres, lo que prácticamente excluía a los blancos de estas zonas:

Así, por virtud del clima, predomina la sangre africana en los pueblos que ahora recorremos, i prospera con sus costumbres libres, sus habitudes indolentes i su indiferencia por los gozes morales e intelectuales, cuya consecución afana tanto i ennoblece a los hijos del Cáucaso. Nada de habitaciones cómodas i adornadas: un techo levantado sobre horcones, entre los cuales se ponen algunas varas derechas que dejen paso al aire esterior; la muelle hamaca sopensa de las vigas; el maíz, el plátano i el pescado metidos de continuo en el fogón, i allí cerca un calabazo con la bebida fermentada, producto de la caña dulce o de la palma-de-vino (Corozo.). Fácil vida que ahorra las penas del trabajo i aleja las inquietudes de la prevision, pero que también prolonga indefinidamente la barbarie. (Ancízar, 1853, p. 455)

Sin temor ni disgusto, así ganaban su alimento los pobladores de la cuenca del río Magdalena (Pérez, 1865, p. 159; Saffray, 1984, p. 55). Estas tierras parecían desmentir la maldición bíblica de ganarse el pan, o más exactamente el plátano y el pescado, con el sudor de la frente. El problema era que esta maldición era necesaria para el progreso y la civilización, y su negación generaba un anatema mucho más terrible: la inmovilidad. Las poblaciones favorecidas por la generosidad de la naturaleza, literalmente vegetaban, según los letrados, incumpliendo los preceptos cristianos y la obligación patriótica de buscar la prosperidad material a través de la producción, la circulación y el consumo de los frutos de la tierra transformados en mercancías.

María Teresa Arcila (2006) ha mostrado cómo los relatos contemporáneos sobre los antioqueños elaboraron un elogio de la dificultad, en el cual la esterilidad de la tierra y lo agreste del territorio los obligaron a luchar o a sucumbir, lucha que había forjado su carácter y que había permitido el progreso de la región; a la par de este elogio, tendríamos, entonces, la maldición de la facilidad; el carácter pródigo de la naturaleza, sumado al temperamento indolente de los pobladores no-blancos habían desestimulado cualquier esfuerzo material y espiritual, lo que había retroalimentado la inferioridad que caracterizaba al territorio y a los pobladores de las tierras definidas como tropicales, es decir, bajas.

La ausencia de población considerada blanca era descrita como una de las causas para la inmovilidad que vivía la cuenca del río Magdalena y en general las zonas cálidas. La indolencia fue descrita como una de las principales características de quienes habitaron estos espacios (Restrepo, 2007). Estas personas eran definidas como seres sin necesidades $y$, por ende, como extraños, tal vez inhumanos, en cuanto que las necesidades y el deseo de satisfacerlas se considera propio de la naturaleza humana. ${ }^{3}$ Era obvio que la civilización y el progreso solo podían venir de afuera, a través de los contactos comerciales o, en otras palabras, del despliegue de los intereses andinos y extranjeros en la región.

Los letrados decimonónicos exigían la presencia de un sujeto parcialmente moderno, productivo e ilustrado, y lamentaban su aparente ausencia. Por supuesto, ellos obviaban las condiciones que hacían posible este tipo de sujetos y trataban un particularismo europeo como un hecho universal y, por ende, obligatorio. A pesar de la relativa ausencia del sujeto moderno en las riberas del río Magdalena, estas estaban habitadas por sujetos de la modernidad, seres en permanente vaivén entre la producción constante de representaciones y prácticas vernáculas para situarse en el mundo y la sujeción al capital, al Estado-nacional y al poder de la letra (Dube, 2006).

Los bogas son un ejemplo claro de estos sujetos de la modernidad. Estos fueron un tipo humano recurrente en los escritos y en la iconografía sobre la zona y, en general, en todos los textos que describieron los diferentes tipos nacionales (Arias Vanegas, 2005; Martínez Pinzón, 2011; Muñoz Arbeláez, 2010; Nieto y Riaño, 2011). El boga es definido por

3 En este sentido, los letrados decimonónicos, en especial los miembros del partido liberal, construirían al hombre en la superficie de proyección de la economía como un ser lleno de necesidades y de deseos. 
Universidad Pedagógica Nacional

Facultad de Humanidades

su fuerza para movilizar los champanes que surcaban el río Magdalena y que fueron durante mucho tiempo indispensables para la comunicación y el transporte en el país. Este tipo fue elaborado a partir de las experiencias de los viajeros letrados y las desiguales relaciones laborales que, combinadas con el lugar, las costumbres y los caracteres raciales se constituían en criterios de clasificación poblacional propios de la colonialidad de poder (Quijano, 2007), es en este sentido que es posible referirse a ellos como sujetos de la modernidad, como sujetos colectivos son el producto de los intercambios comerciales moderno-capitalistas, pero al tiempo son quienes hacen posible el flujo de bienes y personas por el espacio nacional.

Las descripciones hacían énfasis en la fortaleza corporal de los bogas, la cual en no pocas ocasiones era utilizada para asimilarlos o compararlos con los animales salvajes; también se resaltaba la debilidad de sus vínculos sociales y familiares y hasta su lenguaje era considerado bárbaro.

Es el boga un hombre de color, alto, fornido, salvaje en sus costumbres, rival del caimán, cuyo lecho de arena le disputa á palancazos en las playas. De todos los bailes que conoce, ha hecho uno, el $\mathrm{cu}$ rrulao; de las lenguas española, africana é indígena ha hecho un currulao, un dialecto bárbaro. El boga canta indiferentemente salves (sarves dice) á la Virgen ó coplas á las muchachas, á quienes ama en montón, siéndole muy poco importante comenzar unos amores con una y acabarlos con la otra. El boga es honrado, pero ladron y libertino; es decir, no se roba el dinero ni las ropas que se le confían, pero sí el licor y las muchachas. Es sencillo, franco y valeroso. Vive cantando y luchando contra el río y los caimanes; reniega de Dios si hay mal tiempo y le echa viscaínos al rayo cuando le cae cerca. La muerte es para él una cosa muy sencilla: un hombre muere es un champán averiao que se debe echar río abajo. (Vergara y Vergara, 1867, pp. 525-526)

Jose María Samper (1861, pp. 97-98) ya había descrito el currulao, cuyo ambiente ideal no dudaba en situar en el infierno, al tiempo que describía a los danzantes como una zambra de réprobos, que agitaban sus cuerpos en honor a los siete pecados capitales. A la par, también adelantaba la idea de la honradez de los bogas con todo lo que no fuera licor o comida; este valor se transformaba así en un arma de doble filo, puesto que demostraba su desinterés por los bienes materiales, salvo los que colmaban las necesidades y los deseos más básicos. En este sentido, eran indiferentes tanto al bienestar material como espiritual de ellos y sus familias, al tiempo que proclives a los vicios.

La vida de los bogas era, pues, una vida animal y signada por la fuerza, realizaban trabajos agotadores, comían poco, dormían desnudos y tirados sobre las cubiertas de las embarcaciones, insensibles a los millares de insectos, lo cual no podía más que causar la admiración de Miguel Cané, quien simultáneamente no podía dejar de lamentarse del hacinamiento y de la desnudez en la que vivían con sus familias, aunque, a su juicio, la amenaza más grave para el bienestar de los viajeros, que recorrían el río Magdalena, era que

No hay allí recursos de ninguna clase; muchas veces he bajado y viendo huevos frescos, he querido adquirirlos á cualquier precio. Con una calma desesperante, con apatía increíble contestan:-No son para vender; y es necesario renunciar á toda insistencia, porque el dinero no tiene atractivo para esa gente sin necesidades. (1992, p. 80)

En aparente contradicción con Cané, el viajero francés Charles Saffray, quien en 1861 emprendió un viaje por el país, consideraba que los bogas podrían vivir sin trabajar, pero en algunas ocasiones lo hacían porque su afán de placeres y vicios les incitaba a hacerlo para conseguir dinero (1982, p. 56).

Tal vez se podría sugerir una interpretación alternativa, más que irracionalidad, la negativa a vender estaría mostrando una racionalidad de otro tipo, una en la cual el dinero no se privilegiaba, ya que no era lo más necesario para vivir. Ahí estaría justamente la fortaleza de los bogas y en general de los habitantes ribereños que, ante los ojos atónitos de los letrados, participaban con total fluidez en la economía capitalista, al tiempo que mantenían una economía del derroche: 
Así es que estos barqueros del río, los llamados bogas, llevan una existencia de las más duras, pero caracterizada también por una cruda sensualidad, por bestiales costumbres, pues cuanto allegan con faena tan ruda lo despilfarran luego en báquicos excesos. (Röthlisberger, 1993, p. 50)

Dilapidación y gasto improductivo que hacen evidente la exuberancia de la vida más allá de la racionalidad económica liberal; despliegue vital que excede notablemente los límites del trabajo y el ahorro (Bataille, 2007).

Lo importante aquí es que, a pesar de la jerarquización sociorracial que marcaba las relaciones sociales en la república, quienes se autodefinían como blancos estaban sometidos a los designios de los habitantes ribereños, cuando transitaban por el río Magdalena; estos podían transportarlos o no, robarles o no, alimentarlos o no, cuidarlos o entregarlos a su suerte; quienes se adentraban como extraños por estas tierras estaban a merced de quienes representaban como inferiores y no tenían más opción que ruborizarse ante sus expresiones indecorosas y sus licencias sexuales, pronunciadas y practicadas aun en presencia de las señoras, como se quejaba Pérez (1946, p. 34).

Ante la tremenda impotencia de los letrados de las elites, la animalización del otro era una respuesta posible:

Si tomamos el tipo de un boga del Magdalena ó un indio de Cundinamarca, y lo comparamos con un ciudadano educado de Boston, tendremos el punto de donde partimos y aquel á que queremos llegar: la base y la cima de la montaña. La base de la montaña es ésta: vida animal, vicios inveterados, ningún resorte moral, nada de previsión del porvenir, encenagamiento físico y moral, profunda ignorancia [sic] superstición y fanatismo. La cima de la montaña es: actividad intelectual, conocimientos extensos, recursos industriales, emancipación moral, vida moral severa amor á sus semejantes, perpetua aspiración á la perfección, sublime religiosidad de concepciones, estudio de las leyes inmutables y eternas que rigen el universo, y profunda veneración por el autor de ellas (Cortés, 1896, p. 305)
La cima a la que se refería Cortés estaba representada por quienes Medardo Rivas denominó trabajadores de tierra caliente (1899), nombre que, a pesar de lo que un lector desprevenido pudiera pensar, no hacía referencia a los bogas, a los cosecheros o algún otro tipo humano dedicado al trabajo manual, sino a los hacendados, quienes fueron calificados de titanes y descritos como aquellas personas que abatieron las selvas primitivas y casi literalmente trasplantaron a estas los cultivos, la riqueza y la civilización; hombres, y seguramente aquí el término tiene un género definido, que deberían ser cubiertos de honores y reconocimiento. Por supuesto, esta exaltación era un correlato del ocultamiento de los verdaderos trabajadores de tierra caliente que por el contrario eran descritos como indolentes.

Desde la década de 1840, la apropiación privada de zonas en el Alto Magdalena y el piedemonte de los llanos orientales, zonas relativamente cercanas al centro del país, aumentó, en un proceso que fue representado como civilizador, pues apuntaba a la integración económica, la conformación de poblados interconectados y la vida industriosa. Todo ello requería la privatización de la tierra por medio de estos titanes, quienes debían transformar por completo el medio malsano y los habitantes nativos. Se trataba de una doble labor de conquista, apropiación y curación de territorios enfermos y desiertos, y de una población condenada a la indolencia, a la inmovilidad y a la agonía en vida.

Los letrados mencionaban como una de las principales dificultades para explotar estas regiones la falta de trabajadores; la población era considerada escasa y la poca disponible no deseaba satisfacer sus necesidades naturales a través del trabajo, y cuando trabajaba bajo el mando de los hacendados, no se amoldaba a los deseos de estos. La insubordinación de los sujetos de la modernidad aparece de nuevo y pone una traba más a la conquista de las tierras bajas. De forma semejante a la fórmula de que había más territorio que nación y más nación que Estado, se podría plantear que había más territorio que población y más población que brazos, es decir, que sujetos aptos para el trabajo. Salvador Camacho 
Universidad Pedagógica Nacional

Facultad de Humanidades

Roldán lo explicaba claramente: en los países nuevos y despoblados, la concentración de la población era necesaria para que esta gozara de las ventajas de la asociación; la dispersión de la población mantenía la pobreza general y reducía la posibilidad de realizar grandes esfuerzos (1897, p. 145).

\section{Reflexiones finales}

El aumento de la población y de los brazos, dos hechos relacionados pero no equivalentes como se ha planteado, ponía en el tapete dos representaciones muy poderosas y frecuentes: el vacío regional y el escepticismo antropológico (Figueroa Pérez, 2001); en la primera se declaraban como desiertas $y$, por ende, aptas para ser conquistadas, extensas zonas del país; la segunda, resolvía la paradoja de que los desiertos estaban habitados, ya que si bien allí se podían observar seres humanos, estos eran nómadas, salvajes o bárbaros, que no poseían legalmente las tierras en que se encontraban, que no consumían ni producían para el mercado, o lo hacían esporádicamente, en definitiva seres afuera-adentro de la humanidad y de la nación, sujetos de la modernidad, mas no sujetos modernos.

Los esfuerzos por encauzar a los otros, hicieron que todo documento de civilización fuera un documento de barbarie, en tanto, la imposición de la civilización implicó relaciones asimétricas y, frecuentemente, violentas entre las elites letradas y las poblaciones marcadas por una desigualdad que era considerada natural dadas las diferencias sociorraciales y los lugares que habitaban. Estas relaciones pueden ser ilustradas con las formas de sujeción laboral no capitalistas - concertaje, terraje, aparcería, por ejemplo-, aunque insertas en el capitalismo, las cuales contradecían la retórica propia del liberalismo económico predominante entre las elites, como lo ha mostrado Rojas (2001, pp. 219-220).

La justificación de estas formas de sujeción se fundamentaban, en buena medida, en la construcción de los habitantes de la cuenca del río Magdalena como inferiores, dado que su existencia estaba condicionada por las exuberantes características del medio en que vivían, el cual se oponía a la vida civilizada, a lo que se agregaba el influjo de las numerosas enfermedades a las que se veían sometidos y su indolencia constitucional, que les impedía transformarse en verdaderos trabajadores al servicio de sí mismos y de la nación. No se debe olvidar que la condición de posibilidad de la civilización es la construcción, atracción y domesticación de los sujetos marcados como inferiores, sin la existencia de estos, no hay civilización posible, pues ésta es un proyecto expansivo, tanto espacial como temporalmente. De esta forma, los intentos por civilizar la cuenca del río Magdalena, intensificaron su diferencia y al mediano y largo plazo justificaron el abandono estatal y la apropiación privada a través de economías extractivas, proceso que continua hasta nuestros días como lo han mostrado Serje (2005) y Serna Dimas (2006), para quienes las tierras bajas en general, y el valle del río Magdalena en particular, siguen siendo consideradas fronteras internas $y$ tierras de nadie por conquistar.

\section{Referencias}

Ancízar, M. (1853). Peregrinación de Alpha por las provincias del norte de la Nueva Granada en 1850 i 1851. Bogotá: Echeverría.

Arcila, M. T. (2006). El elogio de la dificultad como narrativa de identidad regional en Antioquia. Historia Crítica, 32, 38-66.

Arias Vanegas, J. (2005). Nación y diferencia en el siglo XIX colombiano. Orden nacional, racialismo y taxonomías poblacionales. Bogotá: Universidad de los Andes.

Arnold, D. (2001). La naturaleza como problema histórico. El medio, la cultura y la expansión de Europa. México: FCE.

Bataille, G. (2007). La parte maldita y apuntes inéditos. Buenos Aires: Las Cuarenta.

Camacho Roldán, S. (1897). Notas de viaje (Colombia y Estados Unidos de América). París-Bogotá: Garnier Hermanos, Librería Colombiana.

Cané, M. (1992). Notas de viaje sobre Venezuela y Colombia. Bogotá: Instituto Colombiano de Cultura.

Codazzi, A. (2003). Informe sobre vías de comunicación del Estado de Cundinamarca. En A. Gómez et al (eds.), Geografía física y política de la Confederación Granadina. Estado de Cundinamarca y Bogotá - 
antiguas provincias de Bogotá, Mariquita, Neiva y San Martín (pp. 243-255). Bogotá: Alcaldía Mayor de Bogotá, Departamento de Cundinamarca, Universidad Nacional de Colombia, Universidad del Cauca.

Cortés, E. (1896). Escritos varios, vol. 1. París: Imprenta Sudamericana.

Cuervo Márquez, L. (1886). Lijeras apuntaciones sobre climatología colombiana. Revista Médica, 10(102), 23-33.

Dube, S. (2006). Sujetos de la modernidad. Boletín de Antropología, 20(37), 358-367.

Esguerra, D. (1872). Memoria sobre las fiebres del Magdalena. Santana: Imprenta de D. Díaz.

Figueroa Pérez, J. A. (2001). Del nacionalismo al exilio interior: el contraste de la experiencia modernista en Cataluña y los Andes americanos. Bogotá: Convenio Andrés Bello.

Gómez, J. (1886). Contribución al estudio de las fiebres del Magdalena. Anales de Instruccion Pública de los Estados Unidos de Colombia, 48, 239-246.

Hettner, A. (1976). Viajes por los Andes colombianos (1882-1884). Bogotá: Banco de la República.

Martínez Pinzón, F. (2011). Tránsitos por el río Magdalena: el boga, el blanco y las contradicciones del liberalismo colombiano de mediados del siglo XIX. Estudios de Literatura Colombiana, 29, 17-41.

Muñoz Arbeláez, S. (2010). Las imágenes de viajeros en el siglo XIx. El caso de los grabados de Charles Saffray sobre Colombia. Historia y Grafía, 34, 169-204.

Nieto, M. C. y Riaño, M. (2011). Esclavos, negros libres y bogas en la literatura del siglo XIX. Bogotá: Universidad de los Andes.

Palacio, G. (2001). Introducción. En G. Palacio (ed.), Naturaleza en disputa. Ensayos de historia ambiental de Colombia 1850-1995 (pp. 15-35). Bogotá: Universidad Nacional de Colombia, Instituto Colombiano de Antropología e Historia.

Palacio, G. (2006). Fiebre de tierra caliente. Una historia ambiental de Colombia 1850-1930. Bogotá: Instituto Latinoamericano para una Sociedad y un Derecho Alternativos.

Pérez, F. (1865). Jeografia jeneral de los Estados Unidos de Colombia. París: Librería de Rosa y Bouret.

Pérez, F. (1946). Episodios de un viaje. Bogotá: Biblioteca Popular de Cultura Colombiana.
Quijano, A. (2007). Colonialidad del poder y clasificación social. En S. Castro-Gómez y R. Grosfoguel (eds.), El giro decolonial. Reflexiones para una diversidad epistémica más allá del capitalismo global (pp. 93-126). Bogotá: Siglo del Hombre Editores, Universidad Central, Pontificia Universidad Javeriana.

Restrepo, E. (2007). "Negros indolentes" en las plumas de corógrafos: raza y progreso en el occidente de la Nueva Granada de mediados del siglo xIx. Nómadas. 26: $28-43$.

Rivas, M. (1899). Los trabajadores de la tierra caliente. Bogotá: Imprenta de M. Rivas.

Rojas, C. (2001). Civilización y violencia. La búsqueda de la identidad en la Colombia del siglo XIX. Bogotá: Pontificia Universidad Javeriana, Norma.

Röthlisberger, E. (1993). El Dorado. Bogotá: Instituto Colombiano de Cultura.

Saffray, C. (1984). Viaje a Nueva Granada. Bogotá: Editorial Incunables.

Samper, J. M. (1861). Ensayo sobre las revoluciones políticas y la condición social de las repúblicas colombianas (hispano-americanas): con un apéndice sobre la orografía y la población de la Confederación Granadina. París: Imprenta de E. Thunot y $\mathrm{C}^{\mathrm{a}}$.

Serje, M. (2005). El revés de la nación. Territorios salvajes, fronteras y tierras de nadie. Bogotá: Universidad de los Andes.

Serna Dimas, A. (2006). Ciudadanos de la geografía tropical: ficciones históricas de lo ciudadano. Bogotá: Universidad Distrital Francisco José de Caldas.

Stepan, N. L. (2001). Picturing Tropical Nature. Ithaca: Cornell University Press.

Vergara y Velasco, J. M. (1901). Nueva geografía de Colombia. escrita por regiones naturales. Bogotá: Imprenta de Vapor.

Vergara y Vergara, J. M. (1867). Historia de la literatura en Nueva Granada. Bogotá: Echaverría Hermanos.

Villegas Vélez, A. y Castrillón Gallego, C. (2006). Territorio, enfermedad y población en la producción de la geografía tropical colombiana, 1872-1934. Historia Crítica, 32, 94-117. 